\title{
Albert Camus y la filosofía como forma de vida
}

\author{
Angelo Antonio Moreno León ${ }^{1}$ \\ Natasha Gómez ${ }^{2}$
}

\section{RESUMEN}

Los apuntes que se consignan en este ensayo científico corresponden a los temas tratados en los últimos capítulos de la Tesis doctoral del autor , y conducente al título de "Doctor en Ciencias Filosóficas" por la Universidad de la Habana. Enmarcado en el campo de la historiografía de la filosofía y haciendo uso del método hermenéutico, se analizó la naturaleza de la filosofía de Albert Camus, se le identificó con las tesis directrices de la "filosofía como forma de vida", y se demostró que dicha filosofía se inscribe dentro del camino de este ideal filosófico, rompiendo con el discurso teórico de la filosofía post antigua, particularmente con la filosofía franco-alemana de los siglos diecinueve y veinte. La filosofía de Camus se constituye, pues, como un caso representativo de la tradición filosófica que considera que la filosofía es una práctica destinada a transformar la manera de vivir de sí mismo y de los demás y que busca que la persona se supere a sí misma, que construya una nueva manera de ser-en-el-mundo y tome consciencia de sí como parte de la Naturaleza.

Palabras clave: filosofía, sabiduría, discurso, práctica filosófica, absurdo, ejercicios espirituales

${ }^{1}$ Profesor Investigador Titular, Departamento de Filosofía, Facultad de Humanidades y Artes, UNAH, Tegucigalpa, Honduras. angelo.moreno@unah.edu.hn

2 Asesora, profesora Titular del Doctorado en Ciencias Filosóficas, Facultad de Filosofía e Historia, Universidad de la Habana. nagove@ffh.uh.cu 


\section{ABSTRACT}

The words written in this essay correspond to the topics used in the last chapter author's doctoral thesis with the title of "pHD in philosophic sciences" in La Habana University. Framed in the field of histography of philosophy and using hermeneutics, the philosophy of Albert Camus was analyzed. His thesis guidelines on his "life's philosophy" were identified, and it was demonstrated that his philosophy was enrolled in the right path of the philosophic ideal, ripping apart the theorical speech of the post antique philosophy, particularly in the 19th century French-Germanic philosophy. Camus's philosophy was constituted like a representative affair on the philosophic tradition that considered philosophy as a practice to transform ourselves and other's life style, and which purpose was for the person to overcome itself, for him to build a new way of to-be-in-the-world and to take consciousness of himself as an integral part of nature.

Keywords: philosophy, knowledgment, speech, philosophic practice, absurd, spiritual exercise. 


\section{INTRODUCCIÓN}

Las escuelas filosóficas de la antigüedad crearon una fuerte tradición en torno a la concepción de que la filosofía, más que una reflexión teórica, era una forma de vida. Ser filósofo consistía principalmente en vivir y en actuar de cierta manera buena y no solamente en confrontarse a asuntos meramente abstractos. La etimología del término "filosofía" indica muy bien que el filósofo es aquel que tiende hacia la sabiduría, que vive en constante búsqueda de la felicidad. Además, estos filósofos antiguos le otorgaron a la filosofía una función "terapéutica" que consistía específicamente en: establecer un diagnóstico de la "enfermedad", del estado del hombre desdichado, inquieto, ignorante, conformista; - definir una "norma de salud" que tiene como ideal a la sabiduría y como trasfondo la concepción de la vida buena; - y en elaborar una forma vida que permita la cura del alma del discípulo, a través de una serie de ejercicios filosóficos espirituales (Banicki 2017, 25). Estos ejercicios y prácticas apuntan a corregir las opiniones, los deseos y las acciones del aspirante a la sabiduría (Martínez, Barrera 2008, 14). Pierre Hadot $(1995,13,14,15)$ sostiene que filósofos modernos como Montaigne, Rousseau, Kierkegaard, Nietzsche, al igual que Wittgenstein y otros, cada uno a su manera e incluso inconscientemente, se inscribieron dentro de esta práctica de la filosofía que recuerda a la de los antiguos. Hadot no pronuncia el nombre de Albert Camus en su libro. Sin embargo, eso no impide aproximar su obra alrededor de ese ideal filosófico. En este ensayo se tomará como punto de partida el estrecho vínculo entre la antigüedad filosófica con el ideal de una filosofía como forma de vida, para comprender justamente la naturaleza filosófica de la obra de Albert Camus quien dejó ver claramente su creencia en una filosofía práctica que supedita a la filosofía teórica. Para el desarrollo de la temática, se aproximará la filosofía de Camus a tres de las tesis directrices del enfoque de la filosofía como forma de vida: 1) El discurso filosófico está subordinado a la forma de vida; 2) La forma de vida del filósofo busca como ideal alcanzar la sabiduría; 3) La práctica de la filosofía y la práctica de ejercicios filosóficos espirituales, van de la mano.

\section{METODOLOGÍA}

El ámbito de la historiografía de la filosofía consiste en la reconstrucción de la argumentación de los filósofos del pasado, dándoles un estatus contemporáneo para establecer la posibilidad de una discusión en la que se examinan los problemas y las soluciones planteadas. En el caso de la tesis doctoral que le da luz a este ensayo, se 
toman como base los estudios historiográficos realizados por el filósofo Pierre Hadot y se efectúa una interpretación hermenéutica aplicada a las obras filosóficas Albert Camus, buscando cuestionar la textualidad en sí misma, con relación al autor (proceso de explicación) y al lector (proceso de comprensión). El método hermenéutico (utilizado sobre todo por los filósofos existencialistas para comprender el sentido de la existencia humana), se sirve del paradigma de la novela filosófica y busca, además, interpretar retrospectivamente la filosofía antigua para encontrar el campo de significaciones alrededor del concepto "filosofía como forma de vida", comparando la propuesta de Albert Camus, a través de la construcción histórica que permita comprender la alteridad de sus textos.

\section{El discurso filosófico está subordinado a la forma de vida}

Las obras ideológicas de Camus (El Mito de Sísifo y El Hombre Rebelde) tienen una perspectiva muy práctica. En varios fragmentos, el filósofo justifica teóricamente la prioridad del modo de vida sobre el discurso y la teoría, rasgo que lo aproxima a los filósofos antiguos. En el cuaderno 4 de sus crónicas de 1942, Camus (1996, 93) afirma: "es un hecho que estamos enfermos de nihilismo"; nihilismo que se caracteriza por la ausencia de valores en la contemporaneidad y por la toma de conciencia del carácter maquinal de la existencia y de la certeza de la muerte". Esa confrontación con el mundo y el sentimiento de incapacidad de darle sentido a su vida y de comprender al mundo con sus injusticias y sufrimientos, hacen surgir un divorcio entre el deseo de unidad en el hombre y la irracionalidad objetiva del mundo; a esta confrontación la llama Camus 'absurdo' (1980, 11).

Camus, según atestiguan sus escritos, vivió del nihilismo, comprendió el absurdo y rechazó trascendencia y los juicios de valor del momento. Uno de los factores esenciales que explican el nacimiento de esa idea del absurdo es su desencantamiento del mundo vivido durante su juventud. En una de las páginas escritas por el profesor inspirador de Camus, en las que evoca ciertos aspectos de la vida de su alumno, Jean Grenier $(1968,13)$ escribe lo siguiente: "II n'avait pas à rendre compte de ses sentiments à un Créateur, il n'availt pas à mettre sa confiance dans une Providence. En revanche il avait à se faire reconnaître par les autres" ${ }^{3}$. Las páginas escritas por su maestro Grenier, son el testimonio de esa vida llena de absurdos que llevan a Camus a asumir una rebeldía frente a la existencia misma. En virtud de ello, su obra Mito de Sísifo, es una especie de invitación a perseverar y, al mismo tiempo, a enfrentar con decisión el absurdo, sabiendo que hay posibilidad de buscar primero ponerse

\footnotetext{
3 "El (Camus) no tenía por qué explicar sus sentimientos a un Creador, no tenía por qué confiar en una Providencia. Lo que necesitaba era hacerse reconocer por los otros" (Grenier 1968, 13)
} 
de acuerdo con su propia vida. Sin embargo, Camus tuvo que admitir que una vida vivida únicamente bajo la absurdidad era estéril; que lo que él quería era llegar a las consecuencias lógicas de una "filosofía de la no - significación" (Grenier 1968, 63-63) que obedece justamente al hecho de darle prioridad al modo de vida sobre la especulación misma. Amparado en Nietzsche, Camus $(1980,15)$ afirma que un filósofo se vuelve estimable en la medida en que "debe predicar con el ejemplo", es decir, en la medida en que responde por sus actos, sus discursos y por sus creencias: en el momento en que el filósofo es conducido a que sus principios y su conducta concuerden, el problema del absurdo adquiere una importancia relevante. Así, para Camus la calidad del filósofo se mide con el ejemplo que da de su filosofía. Los griegos son el modelo de este ejemplo: Ellos transmitieron sus enseñanzas a partir de "la vida tangible", a través de la "actitud", de las "costumbres", de las vivencias. Aunque en sus libros Camus no haga alusión a los filósofos griegos, se puede afirmar que se inscribe dentro de esa tradición de la filosofía antigua cuando, junto a Nietzsche, juzga que el filósofo debe vivir su filosofía. En sus "carnets" y en sus crónicas lo confirma más de una vez: "Las filosofías valen lo que valen los filósofos. Cuanto más grande es el hombre, más verdadera es la filosofía" (Camus 1996, 476). El mito de Sísifo es así un ensayo que trata sobre una toma de conciencia particular, para comprender las razones profundas de su itinerario es necesario confrontarse a los mismos problemas. Mientras que el absurdo siga siendo tratado solamente como un problema estrictamente teórico, es imposible reconocer esa invitación a vivir y a creer en la vida. En suma, si se concibe y se comprende que lo que busca la teoría es la transformación de la persona misma, se puede entonces afirmar que hay un enfoque teleológico que tiende a darle la prioridad al modo de vida. En consecuencia, el culmen de la filosofía, su fin como tal, es la aplicación práctica de lo que se ha concebido a través de la razón. Al comienzo del Mito de Sísifo, se hace énfasis en la idea de que el filósofo "debe predicar con el ejemplo", lo que incita a pensar que, para Camus, la filosofía debe primero impregnar la vida de la persona, antes de pretender transformar el mundo. En el cuaderno 4 de Septiembre de 1945 -Abril de 1948, Camus $(1996,209)$ plantea la siguiente pregunta: "¿Podemos transformar el mundo sin creer en el poder absoluto de la razón?" La respuesta es clara: Le corresponde al hombre asumir su condición, buscar su propia libertad, alejado de las ilusiones: "Ni el mismo Dios, si existiese, podría modificar el pasado. Y el porvenir no le pertenece en mayor medida que al hombre" (Camus 1996, 201). El téरos de un pensamiento debe entonces enraizarse en la vida concreta y, según Camus, debe buscar transformar el mundo, después de haber pasado por la transformación del otro. La toma de consciencia lleva así a una "destrucción" de los valores (Blanco llari 2016, 40). Pero esta forma de filosofía no es fácil de asumir ni de vivir, sino que debe ser congruente con los actos mismos: "Es detestable el escritor que habla y saca provecho de lo que no ha vivido 
nunca... El verdadero artista es... el que es "capaz de». Podría ser lo que describe, vivir lo que escribe. El acto en sí lo limitaría: Sería sólo "el que hizo»" (Camus 1996,118).

\section{La forma de vida del filósofo busca como ideal alcanzar la sabiduría}

Habiendo aclarado el vínculo estrecho entre la antigüedad filosófica con el ideal de una filosofía como forma de vida en Camus, se procede ahora a aproximarlo a la búsqueda de la sabiduría la cual, en la práctica de la filosofía antigua, es indisociable. La sabiduría es la norma trascendental que determina la forma de vida en la cual el filósofo alcanza un estado de infalibilidad en el arte de conducir su existencia. Mientras que los filósofos de la época de Camus desarrollaron una antropología teórica sobre la persona, sobre el hombre y sobre el yo mismo sin necesariamente deducir las implicaciones éticas de manera explícita, Camus toma al hombre mismo desde adentro, como objeto de preocupación, buscando transformar sus percepciones y su relación con el mundo. Contrario a ese tipo de antropologías filosóficas, Camus desarrolla en el Mito de Sísifo una concepción, por así decir, muy cercana, muy realista del humano como un ser que está en constante búsqueda de sentido y de unidad para definir así una forma de vida guiada por la preocupación de sí mismo y que busca cambiar la manera de percibir dentro de su interior los eventos de la vida y de los objetos del mundo. La ética del absurdo impele a resistir la extrañeza del mundo con rebeldía y con pasión liberándose así del peso de la esperanza, de las preocupaciones cotidianas y de los ideales metafísicos. Esta manera de vivir coincide con la preocupación de sí mismo de los filósofos antiguos y se prolonga hacia la preocupación por el otro. La pregunta que surge es: ¿El modo de vida propuesto por Camus en el Mito de Sísifo puede realmente aproximarse al ideal de sabiduría, a la excelencia en el arte de vivir la vida, tanto en la interioridad de sí mismo como en las relaciones con los demás, lo que conducirá necesariamente a la felicidad? El hombre absurdo es llevado a cambiar su conciencia de sí: La transforma de manera radical. Camus mismo vivió en carne propia la experiencia del absurdo. Su vida de joven obedece a una tensión irreductible entre lo que él llama su filosofía de evidencia y su filosofía de preferencia (Camus 1996,165). La filosofía de la evidencia, es decir, la filosofía del absurdo repudiaba al mismo tiempo su espíritu y su corazón. A pesar de esa repulsión, dicha filosofía se impone frente a la experiencia de un mundo irracional. A ese respecto, Camus le escribe a su amigo Grenier que el absurdo es una "verdad" de la cual es difícil saber si es posible vivir con ella $(1968,89)$. Sin embargo, declara que conoce otra manera de vivir, es decir la filosofía de preferencia, dejando entrever un cierto eudemonismo ${ }^{4}$, dado su enfoque de equilibrio de unidad y armonía con el mundo. ¿Será esa una prueba de que Camus no vivió como tal según su filosofía del 
absurdo? Herrera $(2011,19)$ sugiere que ese sentimiento del absurdo enfrentó a Camus con la necesidad de dotar de sentido a su vida y, de descubrir "la exigencia metafísica de la unidad, la imposibilidad de asirse a ella y la fabricación de un universo sustitutivo". La filosofía de preferencia de Camus se ve muy reflejada en uno de sus ensayos líricos publicados en 1933 llamado Bodas en Tipasa; allí el filósofo invita a vivir "un día de bodas con el mundo", a "amar sin medida", "estrechar un cuerpo de mujer" y a exaltar la "alegría de vivir", porque hay que "vivir con todo su cuerpo" (Camus 1986, 2-3). El objetivo de esos acentos líricos en el texto es mostrar que esta vida, según el cuerpo, procede de un cambio radical de la relación con el mundo en cuanto que el hombre debe vivir como si fuera una parte del todo que es ese mundo. Si el ideal de todas las filosofías antiguas era justamente llegar a vincular estrechamente al individuo con el mundo, Camus, en esta etapa de su vida, parece interpretar esa vida de placeres enseñada por Aristipo de Cirene, dejando entrever cierto hedonismo sin que se trate de una reactualización consciente del Cirenaísmo. De hecho, el Camus de esta época valoriza el crecimiento de las sensaciones o el placer corporal en movimiento, tal como lo llamaban los cirenaicos; mas no la ausencia de perturbaciones de Epicuro ni el placer del cuerpo en reposo (Diógenes Laercio 1959, 246) invitando más bien a vivir experiencias de armonía, plenitud y de unidad en su filosofía de preferencia.

Antes de escribir el Sísifo, Camus concebía la necesidad de que el hombre se vinculara al mundo para poder alcanzar el estado de felicidad; esta visión de unidad y de armonía se opone al ideal de un "divorcio lúcido", lo que explica el hecho de que en las primeras páginas del Mito de Sísifo, el absurdo sea incompatible con una actitud que consiente el destino dado que el mundo no está habitado por el sentido. Con la reinterpretación del Mito, al final de la obra, Camus ilustra que el absurdo admite cierta forma de unidad con el mundo, pero no una renuncia a la rebelión, ni a la voluntad ni a la pasión, y presenta al hombre absurdo como alguien capaz de sentir felicidad y "paz interior". El final del Mito de Sísifo se abre sobre la posibilidad de vivir una existencia absurda que atraviesa los caminos difíciles y se aproxima a la felicidad, uniendo así a las filosofías del absurdo con la filosofía de la preferencia y pasando de una comprensión hedonista (sin renegar de ella), a una concepción estoica de la felicidad, no bajo un enfoque intelectualista ni racionalista sino más bien dentro de su ideal del "consentimiento". Pero hay que ser prudentes en cuanto a esta aproximación al estoicismo, debido a que Camus no comparte el consentimiento ingenuo que el estoicismo hace frente al mundo. Si en el seno del estoicismo, el absurdo es un

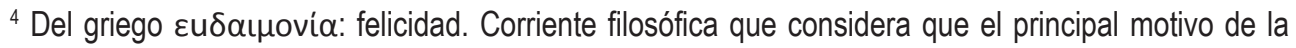
conducta del hombre es el anhelo de felicidad. 
concepto imposible de pensar y, si en el horizonte cultural de la modernidad es difícil aceptar la visión física racionalista estoica, la rebelión contra el absurdo es incompatible, estrictamente hablando, con el consentimiento estoico de la Naturaleza universal. Para los estoicos querer cambiar el orden del mundo, más que consentirlo, significa rebelarse contra Dios, contra la Razón presente en todas las cosas y en todos los eventos del cosmos. En ese orden, las únicas cosas que dependen de nosotros y sobre las cuales es posible ejercer un control, son las operaciones del alma como "nuestras opiniones, nuestras inclinaciones, nuestros deseos, nuestras repugnancias; en una palabra, todas nuestras acciones: lo que no depende son los cuerpos, los bienes, la reputación, las dignidades; en fin, todo aquello que no es obra nuestra" (Epicteto 1802, 69). Debido al carácter sistemático de esta doctrina y a la lógica y solidaridad de sus elementos, es muy difícil y arriesgado aproximarla a algo que se pareciese a un "estoicismo moderno". Intentarlo implicaría aislar la ética de los estoicos de su física y de su lógica. Es posible, sin embargo, aproximar la filosofía camusiana a varios elementos de la ética estoica para entender mejor el modo de vida propuesto en el Mito de Sísifo. Por ejemplo, Camus invita al hombre a replegarse dentro de su fuero interior, a que se construya una fortaleza en sí mismo, a perseverar en su ser y a enfrentar el mundo más que a evitarlo y huir de él. Esta ética incita al hombre a actuar dentro del marco de la conciencia como lugar de la verdadera vida buena. Por eso Camus afirma que "la voluntad humana no tenía más finalidad que la de mantener la conciencia" $(1980,152)$. El "repliegue interior", y la "tenaz negación de un mundo amenazante", son los rasgos que caracterizan a la ética del absurdo en la que el hombre retorna dentro de sí mismo, continúa su lucha, alcanza su felicidad a través del esfuerzo de la voluntad; que diga "sí" porque "su esfuerzo no terminará nunca" (Camus 1980,162). Ese "si" es la prueba de la tenacidad de la voluntad del hombre por mantener el absurdo. Sin una felicidad relativa, el hombre está destinado a la esterilidad. La enseñanza mayor del Mito de Sísifo es esta: Cuando el hombre cree que ya no puede ejercer ninguna influencia sobre el mundo y sobre los eventos exteriores, toma conciencia de que le queda todavía la posibilidad de ejercer el poder sobre sí mismo. Esta filosofía admite la importancia ética de un consentimiento de la irrevocabilidad del absurdo con la conciencia de no poder cambiar el mundo en sí, y sin dejar de lado el cuestionamiento que exige la rebelión. A pesar de que para los estoicos el acto de consentir está íntimamente vinculado al alcance de la felicidad coincidiendo así con la postura de Camus, la visión del mundo difiere, ya que aquellos lo conciben de manera muy racional mientras que, para éste, el mundo es irracional. Sin embargo, Camus comparte la visión de los estoicos sobre el hecho de enfrentar el mundo y consentirlo, envés de evitar los dolores que provocan el descubrimiento del absurdo como lo harían los epicúreos. Además, la ética del absurdo promueve una filosofía de la voluntad al igual que los estoicos, dándole un sitio grande a la 
modalidad del consentimiento dentro de esa lógica de la voluntad, culminando así en el mismo espíritu del consentimiento relativo que caracteriza a la sabiduría estoica. Igualmente, se puede afirmar que el modo de vida que presenta el Mito de Sísifo se propone llegar a la felicidad no únicamente en el sentido de un estado subjetivo de bienestar, sino como un estado que se equipara a la excelencia dentro de la relación consigo mismo, con la aceptación del mundo, recordando así la serenidad y la eudaimonia de estoicos más que el placer de los epicúreos. La autenticidad y la lucidez de este modo de vida implican necesariamente la valorización del perfeccionamiento de sí, a través del recogimiento, del "diálogo consigo mismo" que busca alcanzar la felicidad del hombre reconciliado con su destino. El hecho de que al final del Mito de Sísifo no se haga ninguna alusión a los placeres del cuerpo permite considerar que Camus, redireccionando la relación entre la filosofía de evidencia y la filosofía de preferencia aproxima el modo de vida absurdo a la felicidad como forma de excelencia para asumir la vida interior del hombre que busca la realización de una percepción diferente del mundo, la tranquilidad del alma y la autosuficiencia. Anclada en la finitud humana, esta sabiduría no debe ser equiparada a un estado de perfección, sino más bien a un estado de "lucidez frente a la existencia" (Camus 1980,17). La conciencia del absurdo se expresa a través de esa lucidez y la perseverancia en ella, vinculada a la felicidad.

\section{La práctica de la filosofía y la práctica de ejercicios filosóficos espirituales van de la mano}

Los ejercicios espirituales eran muy importantes para los filósofos antiguos; se trataba de prácticas voluntarias de naturaleza física, intuitiva o discursiva que buscaban preparar al alma para convertirse a la sabiduría. La tradición de los ejercicios espirituales debido a su carácter "universal" fue marcada por una cierta continuidad a pesar del ocaso de las escuelas antiguas. Los ejercicios espirituales (de abstinencia sexual o de comida, cuidado de sí mismo, examen de conciencia, expansión de sí y de meditación) siguen estando presentes a lo largo de la historia y son actuales para que el humano pueda disponer de ellos. Camus los practicó y vivió eventos muy particulares que le hicieron cambiar radicalmente su punto de vista sobre el mundo. Además, mezcló ejercicios de diferentes horizontes y de diferentes tradiciones y le dio una gran importancia a la práctica de algunos ejercicios corporales que buscaban al mismo

5 "Hadot $(1995,197)$ afirma que "El diálogo consigo mismo es una costumbre generalizada en toda la Antigüedad. (...) La meditación forma parte de un conjunto de prácticas que no son todas del orden del discurso, pero que siempre son testimonio del compromiso personal del filósofo y, para él, un medio de transformarse y de influir sobre sí mismo." 
tiempo mejorar la salud de su cuerpo, el dominio de sí mismo, el control de las pasiones, principalmente en lo que atañe a la relación con las mujeres y con la comida ${ }^{6}$.

En su correspondencia con Grenier $(1968,121)$, se queja de "ser superado por su cuerpo" y le confía que ha tratado desde hace bastante tiempo de superar sus debilidades a través del cuidado del cuerpo, del ejercicio físico y la práctica del fútbol. Y en una parte de los Carnets I, escritos entre 1935 y 1942, Camus $(1996,514)$ reconfirma la preocupación hacia el cuidado de su cuerpo con el fin de liberarse de sus vanidades y de sus bajezas. Unos años más tarde él mismo confiesa que trató de curarse a través del ejercicio de la voluntad: "Tengo dos o tres pasiones que se pueden juzgar culpables, que, a mi parecer, lo son, y de las que intento curarme ejercitando la voluntad. A veces lo logro" (Camus 1996, 298). También cultivó la ascesis en la comida: "cuando la ascesis es voluntaria, se puede ayunar seis semanas (el agua basta). Cuando es obligatoria (hambre), no pasa de diez días" (Camus 1996, 481). Durante esas ascesis, Camus afirma descubrir su "reserva de energía real", dando a comprender así que tomó conciencia del poder de la fuerza de su voluntad. Y ejerció la ascesis dirigida hacia la sexualidad: "La sexualidad desenfrenada lleva a una filosofía de la no significación del mundo. Por el contrario, la castidad le devuelve un sentido (al mundo)" (Camus 1996, 141). Y más adelante (1996, 592), sostiene que "hay que imponerse un mes de ascesis en todos los sentidos" antes de entregarse a la escritura y a la reflexión. Igualmente, en los carnets I (1996, 592), escribe: "Renunciar a esa certidumbre: la atracción femenina". La importancia de la ascesis nos recuerda, en cierta manera, a los ejercicios epicúreos ${ }^{7}$. Aunque Camus no asocia la felicidad a la ataraxia, parece preferir más bien el acuerdo con el mundo del estoico, por el hecho de que él no elaboró una tipología de los deseos. Camus parece valorizar la cantidad, el confort y la abundancia a pesar de su gran austeridad; de igual modo, esos placeres no parecen ser prohibidos por el epicureísmo, ya que "ningún gozo es malo en sí mismo, pero los actos causantes de determinados gozos conllevan muchos más dolores que gozos" (Epicuro 2012, 89-90). Significa que los placeres representan un peligro por los sufrimientos que pueden causar; por esto mismo, Epicuro nunca invita a llevar una vida de desenfrenos. Aunque Camus no retoma algunos elementos del epicureísmo, se pueden encontrar huellas de práctica de ascesis, lo que lo acerca bastante a esta filosofía tanto por el objeto (ciertos deseos

\footnotetext{
${ }^{6}$ Este pasaje puede confirmar la hipótesis: "La vida sexual fue dada al hombre tal vez para desviarlo de su verdadero camino. Es su opio. En ella todo se adormece. Fuera de ella, las cosas recobran su vida." (Camus, 1996, 140)

${ }^{7}$ En Carnets I (mayo de 1935 - febrero de 1942), en la página 549, Camus anota lo siguiente: "Ver Epicuro (ensayo)".
} 
bien definidos) como por su objetivo (el ideal del dominio propio) ${ }^{8}$. Esta alternancia entre la ascesis y el placer realizada por Camus lo aproximan al epicureísmo: Mientras que éste limita la ascesis a los deseos de la comida, del sexo y de la lujuria, aquellos creen que la ascesis debe ser practicada idealmente sobre el conjunto de deseos que no buscan satisfacer el deseo de beber y de comer (los deseos necesarios para la vida $)^{9}$. Camus hace uso de un estoicismo equilibrado en su práctica de ejercicios, mediado por una especie de epicureísmo. Otra pista que permite confirmar lo enunciado anteriormente sobre la práctica de la askesis: Camus escribe, literaria o filosóficamente obedeciendo a criterios formales sobre un ejercicio espiritual que busca producir un efecto en su "alma" y en la de quien lee sus escritos. Este ejercicio lo acentúa en la obra de arte la cual, según él, pude transformar a su creador y al mundo. Para él, el escrito literario no debe consistir en contar "historias", sino en crear el "universo propio": "Los grandes novelistas son novelistas filósofos, es decir, lo contrario de escritores de tesis" (Camus 1980, 34). Ellos tienen la función de crear en el lector una "sensación" que haga cambiar su percepción del destino. La función del arte "hace que el espíritu salga de sí mismo y lo coloca frente a otro, no para que se pierda en él, sino para mostrarle con un dedo preciso el camino sin salida en que se han metido todos (Camus 1980,128). El escrito no tiene como fin transmitir una doctrina y hacer que el alma se acoja a ella, como lo creían los antiguos: La grandeza del escrito consiste en iniciar en el lector una toma de conciencia sin enseñarle ningún dogma, preparándolo así para que se sitúe él mismo en el camino de una filosofía ${ }^{10}$.

Pero esta transformación no se opera solamente en el espíritu del lector, sino también en el del creador: "El artista, lo mismo que el pensador, se empeña y se hace en su obra" (Camus 1980,129). Gran parte de los Carnets escritos por Camus, hoy recopilados en tres volúmenes que abarcan sus meditaciones, sus apuntes, sus borradores desde 1835 hasta 1959, hacen recordar a los Hipomnemata, esos discursos escritos

\footnotetext{
${ }^{8}$ Epicuro no utiliza el concepto de dominio de sí (enkrateia); más bien, se refiere al ideal de la autarkeia; pero los ejercicios epicúreos apuntan, de alguna manera, hacia la misma forma de dominio de los deseos que Camus buscaba cultivar.

${ }^{9}$ Vale la pena recordar el siguiente fragmento de Epicuro: "Pues ni las bebidas ni las juergas continuas ni tampoco los placeres de adolescentes y mujeres ni los del pescado y restantes manjares que presenta una mesa suntuosa es lo que origina una vida gozosa sino un sobrio razonamiento que, por un lado, investiga los motivos de toda elección y rechazo y, por otro, descarta las suposiciones, por culpa de las cuales se apodera de las almas una confusión de muy vastas proporciones." (Epicuro 2012, 90). La autarkeia epicúrea busca que el hombre aprenda a satisfacerse de un régimen que suprime el dolor que proviene de la falta de bebida y de comida, de un abrigo y de un vestido, que suprimen el dolor que viene del frío y de las demás cosas que le permitirán no tener perturbaciones. ${ }^{10}$ Camus (1998, p. 381), es muy enfático en el papel que debe jugar un artista-filósofo: "El artista es como el dios de Delfos: "No muestra ni esconde: significa"'.
} 
o cuadernos de notas en los que los estoicos plasmaban sus meditaciones, sus principios sobre la vida buena para que el filósofo pueda modificar sus juicios, sus deseos y sus acciones. Se trata, así, de un ejercicio espiritual muy cercano al de los estoicos ya que Camus anotaba sus fórmulas, sus preocupaciones, sus meditaciones, su diario vivir, muchas de ellas con el fin de fortalecer su voluntad y acercarse a la sabiduría. Camus $(1996,176)$ practicó, además otro tipo de ejercicio de reconciliación interior con la conciencia de la muerte como situación límite del humano; tal ejercicio prepara y se adelanta a ese "mal" trayendo como resultado la satisfacción, el gozo del alma, al saber que puede llegar la muerte en ese instante y que se está listo para ello. Se trata de un ejercicio pasivo de cuidado de sí mismo y de aceptación del presente que concuerda con el planteamiento de los estoicos, quienes aprendían a no tener miedo "de pensar por anticipado los acontecimientos (...) para decirse (...) que males futuros no son males, pues no están presentes, y (...) que los acontecimientos, como la enfermedad, la pobreza y la muerte, que los demás perciben como males, no son males" (Hadot 1995, 154). El tema sobre la conciencia del presente fundamentado en la presencia del cuerpo y la crítica al pensamiento y a la esperanza (que entran dentro del campo de lo posible) se articula dentro del espacio del ejercicio de anticipación a la muerte: "el cuerpo debe podrirse" (Camus 1996, 562). Esta reflexión trae a la memoria el fragmento 4.41 de Marco Aurelio $(1977,45)$ que dice: "Eres un alma diminuta que lleva un cadáver, como decía Epicteto".

Así, no es arriesgado afirmar que gran parte de los ejercicios relatados por Camus en los Carnets I, II y III, lo que buscan es ayudarle a tener conciencia de sí mismo para convertirse en amo de sí mismo, paso indispensable para lograr la vida buena. Un fragmento que da testimonio de eso es el siguiente: "Me esfuerzo por llegar hasta el final en esta presencia mía conmigo mismo; me esfuerzo por tenerla frente a todas las facetas de mi vida; el precio difícil es la soledad, tan difícil de soportar" (Camus 1996, 489) Y más adelante: "La voluntad es también una soledad" $(1996,597)$. La soledad, el retiro voluntario que implican sacrificio ayudan a que los hombres tomen conciencia de su estado moral y a que cambien, llevando como ejemplo las reglas de vida absurda: Esa es la condición, según Camus, para alcanzar el ideal de consentimiento relativo al mundo. En los Carnets II escribe: "10 de febrero. Cuatro meses de vida ascética y solitaria. Ganan con ello la voluntad y el espíritu. (Camus 1996, 161). Y mucho más adelante: "(...) Lo demás, la salud, la integridad, hasta la pureza, son fruto de una voluntad, y de una voluntad que no debe aflojar nunca. El hombre honesto, el que no contamina a nadie, es el que se permite menos distracciones" (1996, 239). Para Camus la condición para estar desnudo delante del mundo y, viceversa, es estar despojado. Se trata aquí del ideal de conciencia consigo mismo y del ideal de expansión de sí, unidos por la felicidad y el consentimiento del mundo. Se enfatiza 
la importancia de la presencia de sí mismo como ejercicio que sirve como toma de conciencia fundamental de la situación en el mundo. En su obra Bodas en Tipasa, Camus $(1986,6)$ elogia reiteradas veces el placer del goce del cuerpo y el placer de existir en un mundo que, sin ser racional, merece ser amado. Es esta una forma de invitar al lector a extender las fronteras de la percepción humana y de tomar conciencia de la pequeñez de la individualidad humana y de la belleza del mundo.

\section{CONCLUSIONES}

El arte de filosofar de Camus es un ejemplo de actualización del ideal práctico de la filosofía que busca que, en medio de la absurdidad y de fatalismo de una vida sin sentido contra la que no se puede hacer nada, el hombre, a través de un verdadero trabajo de conciencia de sí mismo observe el mundo con una mirada nueva, que aprenda a cohabitar consigo mismo, con los otros y con la naturaleza a pesar de las dificultades de la vida diaria. Todo eso, apoyado en prácticas destinadas a la transformación de su propia existencia. Después de este análisis hermenéutico, se puede confirmar que Camus hace corresponder al mismo tiempo, el pensamiento y el buen vivir, en busca de la felicidad y que actualiza en estos tiempos de catástrofe, de guerras y de violencia, las actitudes existenciales experimentadas por los primeros filósofos griegos, rebelándose, con pasión y lucidez, contra el nihilismo de su tiempo. De esta manera, es posible concluir afirmando que el telos del pensamiento de Camus es: Vivir y definir un modelo contemporáneo de sabiduría y de virtud que busca la excelencia en la relación consigo mismo, la felicidad y la lucidez; todo esto, dentro del respeto y la defensa activa del poder de rebelión del prójimo.

\section{REFERENCIAS BIBLIOGRÁFICAS}

Blanco llari, J. I. (2016). Preservar la experiencia: sobre el imperativo metodológico de Albert Camus». Revista Franciscanum 166, Vol. LVIII, 166

Banicki, K. (2017). Filosofía como terapia: hacia un modelo conceptual. Revista Konvergencias, Filosofía y Culturas en Diálogo, 24.

Camus, A. (1980). El mito de Sísifo. Buenos Aires, Argentina: Losada

Camus, A. (1996). Obras 3, El hombre rebelde. Madrid, España: Alianza Editorial

Camus, A. (1996) Obras, 4. Madrid, España: Alianza Editorial

Camus, A. (1996). Carnets I (mayo 1935 - febrero 1942). Madrid, España: Alianza Editorial 
Camus, A. (1998). Carnets III (marzo 1951 - diciembre 1959). Madrid, España: Alianza Editorial

Camus, A. (1986). Bodas. Barcelona, España: EDHASA

Diógenes, Laercio. (1959). Vidas, opiniones y sentencias de los filósofos más ilustres. Madrid, España: Aguilar

Epicteto (1802). Manual. Madrid, España: Oficina de Aznar

Epicuro (2012). Obras Completas. Madrid, España: Cátedra Grenier, J. (1968). Albert Camus, Souvenirs. Paris : Gallimard Hadot, P. (1995). ¿Qué es la Filosofía Antigua? México: Fondo de Cultura Económica Hadot, P. (2006). Ejercicios Espirituales y Filosofía Antigua. Madrid, España: Siruela Herrera P. A. (2011). La estética de Albert Camus. España: Universidad de Salamanca Kant, E. (2007). Crítica de la razón pura. Buenos Aires, Argentina: Colihue Marco Aurelio. (1977). Meditaciones. Madrid, España: Gredos Martínez, Barrera, J. (2008). La Filosofía como praxis una reconsideración de Pierre Hadot. Mendoza, Argentina: Centro de estudios de Filosofía Clásica 